\title{
Teknoloji Bağımlılığının Çeşitli Yaş Gruplarındaki Çocuklara Etkileri Hakkındaki Ebeveyn Görüşseri
}

\author{
Ömer GÖKEL ${ }^{1}$
}

\begin{abstract}
Özet: 21. Yüzyıldaki teknolojik gelişmelerin, dijitalleşme ve bilişim teknolojilerindeki ilerlemenin hızı ve sunduğu imkanların çeşitliliğinden vazgeçebilmek insanoğlu için zor bir seçenek olmuştur. Özellikle bu çağ içinde doğan ve sosyalleşen çocuklar ve ergenlerin teknolojiyle iç içe büyümesi onların yaşamlarının vazgeçilmezi haline gelmiştir. Ancak bu vazgeçilmez özellikle çocuklar ve ergenler üzerinde çeşitli olumsuz etkilere neden olmaktadır. Teknoloji bağımlılı̆̆ı bunlardan en önemlisidir. Teknolojik araçların (internet, bilgisayar, tablet, akıllı telefon, vb.) uzun süre kullanımının çocukların gelişimi ve sağlığı üzerindeki olumsuz etkileri çeşitli araştırmalarla kanıtlanmıştır. Çocukların teknolojik araçları uzun süre ve çeşitli pozisyonlarda kullanmaları onların bedensel gelişim (kas-iskelet sistemi) aşamalarında problem yaşamalarına, fiziksel sorunlar, obezite ve ruh sağlıklarında bozulma gibi sağlık risklerine yol açabilmektedir. Bu çalışma da, söz konusu teknoloji bağımlılığının çocuklar üzerindeki olumsuz etkileri hakkında ebeveynlerin görüşlerini ortaya çıkarmayı amaçlamıştır. Araştırmada veriler yarı yapılandırılmış görüşme ile toplanmış ve içerik analiziyle incelenmiştir. Araştırma sonucunda özellikle 7-18 yaşındaki çocuklarda görülen teknoloji bağımlılığında ebeveynlerin önemli etkilerinin olduğu tespit edilmiştir.
\end{abstract}

Anahtar kelimeler: teknoloji, bağımlılık, teknoloji bağımlılığı, gelişim

\section{Parental Opinions on the Effects of Technology Addiction on Children of Various Age Groups}

\begin{abstract}
It has been a difficult option for human beings to abandon the technological developments in the 21 st century, the pace of progress in digitalization and information technologies and the variety of opportunities. Technology has become an indispensable part of their lives especially children and adolescents who born and socialized in this age. However, this indispensable causes various negative effects especially on children and adolescents. Technology addiction is the most important of these. The negative effects of long-term use of technological tools (internet, computer, tablet, smartphone, etc.) on the growth and health of children have been proven by various studies. Children's use of technological tools for a long time and in various positions can lead to problems in their physical development stages (musculoskeletal), health problems such as physical problems, obesity and impaired mental health. In this study, it was aimed to reveal parents' opinions about the negative effects of this technology addiction on children. The data were collected by semi-structured interviews and analyzed by content analysis. As a result, it has been found that parents have significant effects on technology addiction for 7-18 years old children.
\end{abstract}

Keywords: technology, addiction, technological addiction, growing

${ }^{1}$ Yrd. Doç. Dr., Kıbrıs Sosyal Bilimler Üniversitesi, Eğitim Bilimleri Fakültesi, Rehberlik ve Psikolojik Danışmanlık Bölümü

Address of correspondence/ Yazışma adresi: Yrd. Doç. Dr. Ömer Gökel, Kıbrıs Sosyal Bilimler Üniversitesi, Eğitim Bilimleri Fakültesi, Rehberlik ve Psikolojik Danışmanlık Bölümü, Lefkoşa/Kıbrıs, Email: omer.gokel@kisbu.edu.tr

Date of received/ Geliş Tarihi: 04.11.2019, Date of Revision/ Düzeltme Tarihi: 25.12.2019, Date of acceptance/ Kabul Tarihi: 06.01.2020

Citing/ Referans Gösterimi: Gökel, Ö. (2020). Teknoloji Bağımlılı̆̆ının Çeşitli Yaş Gruplarındaki Çocuklara Etkileri Hakkındaki Ebeveyn Görüşleri. Kıbrıs Türk Psikiyatri ve Psikoloji Dergisi, 2(1): 41-47 doi:10.35365/ctjpp.20.2.6 


\section{Giriş}

Teknolojik gelişmelerin ve yeniliklerin insanlık tarihindeki önemi yadsınamayacak kadar büyüktür. Bu gelişmeler ve yeniliklerin çeşitliliği ve insanın yaşamını kolaylaştıran teknolojinin sunduğu imkânlardan vazgeçebilmek neredeyse imkânsız hale gelmiştir (Haug ve ark., 2015; Yayla, 2017). Böylece teknolojik araçlar (internet, akıllı telefonlar, tablet, bilgisayarlar vb.) da insanın vazgeçilmez bir parçası ve insanların var oluşunu teslimalan bir araç haline gelmiştir. Bu teslim alınış da en uç seviyelere ulaşarak bağımlılık haline dönüşmüştür (Asslan ve Yazıcı, 2016; Aksu ve Işıklı, 2019; Anandi ve Gududur, 2018; D'Arcy ve Gupta, 2014; Gerhart, 2017).

$\mathrm{Bu}$ durum sonucunda da bazı etkinliklerin uzun sürelerle kullanılması veya yapılması insanların yaşam kalitesini bozabilmekte ve çeşitli olumsuz sonuçlara neden olabilmektedir (Anandi ve Gududur, 2018; Kuss, Griffiths, ve Binder, 2013; Erses ve Müezzin, 2018; Techatassanasoontorn ve Tanvisuth, 2010; Vaghefi ve Lapointe, 2014; Zwanenburg, 2013). Teknolojik araçların uzun süre kullanımı da farklı türlerde bağımlılığa etki edebilmektedir. Bu bağımlılıklar arasında internet, dijital oyunlar, cep telefonu, bilgisayar, televizyon vb. bağımlılıklar son günlerde en çok karşılaşı1lan bağımlılıklardır (Aslan ve Yazıcı, 2016; Müezzin, 2017; Tarafdar, Gupta ve Turel, 2013; Şahin, Özdemir, Ünsal ve Temiz, 2013; Winkler, Dörsing, Rief, Shen, ve Glombiewski, 2013).

Teknolojik bağımlılıklar davranış tabanlı bağımlılıklar içerisinde kabul edilmektedir. Bu çeşit bağımlılıklarda kişi, televizyon seyrederek pasif bağımlı; dijital oyunlar, internet, cep telefonu, bilgisayar gibi teknolojik araçlarla da aktif bir teknoloji bağımlısı olabilmektedir (Bachleda ve Darhiri, 2018; Öztürk, 2017). Teknoloji bağımlılığ1 gibi davranış tabanlı bağımlılıklar veya davranışlar, genellikle ebeveynler ve sosyal çevre tarafindan bir alışkanlıkveya ruhsal yönden sakinleşme biçimi şeklinde düşünülerek göz ardı edilebilmektedir. Ancak, son zamanlarda yapılan çalışmalarda psikolojik bir bağımlılık veya alışkanlık şeklinde görülen durumların alkol, sigara, uyuşturucu gibi maddelere karşı oluşan bağımlılıklarla aynı seviyede olduğu, beyindeki nörokimyasal mekanizmalarla ve yapısal değişimlerle ilişkili olduğu tespit edilmiştir (Bachleda ve Darhiri, 2018; Goodwin, 2018; Hamissi, Hosseini, Babaie ve Babaie, 2013; Müezzin, 2012).

\section{Araştırmanın Amacı}

Teknoloji bağımlılı̆̆ıyla ilgili birçok araştırma yapılmasına rağmen, bu bağımlılıktaki ebeveyn etkisine yönelik çalışma sayısı sınırlıdır. Özellikle KKTC boyutunda hiçbir çalışma bulunmamaktadır. Gelişme çağındaki çocukların birincil sosyalleşmesinde ve model almada en önemli evre olan aile ortamındaki ilişkiler ve ebeveynlerin teknolojiye olan tutumlarının çocuklar üzerindeki etkileri bu zamana kadar sinırlı sayıda incelenmiştir. $\mathrm{Bu}$ çalışmanın alandaki boşluğu doldurması açısından önemli olacağı düşünülmektedir. Teknoloji bağımlılığı, kapsadığı unsurlar olarak geniş bir çerçevede ele alınmalıdır. Bu araştırma kapsamında da teknoloji bağımlılı̆̆ının en yoğun olduğu alanlar/araçlar olarak ele alınan cep telefonu, internet, bilgisayar ve dijital oyunlarla ilgili bağımlılık seviyesinin ailevi durumlarıyla ilişkili olup olmadığı araştırılmış ve ayrıca teknoloji bağımlılığının bireylerin fiziksel, bilişsel ve psikososyal gelişimleri ile başarı (akademik/iş) seviyelerine etkilerinin ortaya çıkarılması amaçlanmıştır.

\section{Yöntem}

Araştırmada nitel araştırma yöntemlerinden yarı yapılandırılmış görüşme tekniği kullanılmıştır. Toplanan veriler ise içerik analizi ile çözümlenmiştir.

\section{Çalışma Grubu}

Araştırmanın katılımcıları, küme örneklemi yöntemiyle belirlenen KKTC'nin Gazimağusa ilçesindeki ilkokul, ortaokul ve liselerdeeğitim gören öğrencilerin ebeveynlerinden oluşan 72 kişiden oluşmuştur.

\section{Veri Toplama Aracı}

Araştırmada veri toplama aracı olarak beş adet açık uçlu sorudan oluşan bir görüşme formu hazırlanmıştır. Görüşme formunun iç geçerliliği için alanında uzman iki kişiye başvurulmuştur. Uzmanların inceleme ve değerlendirmesi neticesinde soruların net, anlaşılır ve yeterli olduğu kanısına varılmışırı. Formdaki soruların net ve anlaşılır olup olmadığı, cevapların soruların yanıtlarını karşılayıp karşılamadığını belirlemek için de görüşmeler kayıt altına alınarak bir döküm oluşturulmuş ve bilgisayar ortamında yazılı hale getirilmiştir. Elde edilen dökümler incelenmesi için farklı iki uzmana verilmiş ve soruların net ve anlaşı1ır olup olmadığı, verilen yanıtların soruların cevaplarını karşılayıp karşılamadığı, konuyu tam olarak yansıtıp yansıtmadığı hususunda $\% 88$ oranında uygunluk cevabı alınmıştır. $\mathrm{Bu}$ bağlamda çalışmada kullanılan görüşme formundaki soru maddelerinin geçerliği sağlanmıştır. Bu aşamadan sonra formun ulaşılmak istenilen amacı sağladığı değerlendirilerek verilerin toplanması ve analizi sürecine geçilmiştir.

\section{Verilerin Analizi}

Yarı yapılandırılmış görüşme formundan elde edilen veriler içerik analiziyle çözümlenmiştir. İçerik analizi sözel, yazılı ve diğer materyallerin nesnel ve sistematik bir şekilde incelenmesine olanak tanıan bilimsel bir yaklaşımdır. Böylece toplanan veriler derinlemesine analiz edilir ve bazı temalar ve boyutlar ortaya çıkarılabilir. İçerik analizinde, birbirine benzer nitelikteki kelime, cümle ya da paragraftaki ifadeler belli temalar etrafında birleştirilir, kodlanır ve okuyucu kitlesinin anlayabileceği bir şekilde düzenlenerek yorumlanır (Tavşancıl ve Aslan, 2001; Akt: Sert, Kurtoğlu, Akıncı ve Seferoğlu, 2012).

Yarı yapılandırılmış görüşme için belirlenen katılımcıların fazla olması nedeniyle verimlilik açısından 7 farklı grup oluşturulmuştur. Ebeveynler için aşağıda belirtilen soruların her biri tema olarak belirlenmiştir;

- Siz ve çocuklarınız hangi tür teknolojik araç kullaniyorsunuz ve bunlarla ne kadar vakit geçiriyorsunuz?

- Sizin ve çocuklarınızın teknolojik araçları kullanma nedenleri nelerdir?

- Çocuklarınızı teknolojik araçları kullanmalarına müsaade etme nedenleriniz nelerdir? 
- Teknolojik araçların sizde ve çocuklarınız üzerinde ne gibi olumsuz etkileri olabilir?

- Sizin ve ailenizin teknolojik araçlara bağl1 olarak yaşam biçiminizde ne gibi değişiklikler olabilmektedir?

Görüşmeler 60-120 dakika arasında gerçekleşmiş ve katılımcıların onayını müteakip ses kayıt cihazı ile kaydedilmiştir. Kayıtlardan elde edilen bilgilerin temel içerikleri ve içerdikleri mesajlar yazılı hale dönüştürülmüştür. Görüşme dökümlerinden sonra elde edilen bulgular, alandan bir uzmana inceletilerek hatalı veya eksik kısımların kontrolü yapılmıştır. Daha sonra bu veriler kendi içinde anlam ifade eden bölümlere ayrılarak kodlanmış ve özetleme yapılmıştır. Özetleme ve katılımcı görüşlerinin bazılarıyla ilgili dipnot kullanılmış, kimliklerinin gizli tutulması maksadiyla da isim kullanılmamış, yaşları ve cinsiyetlerine ilişkin kodlama yapılmıştır [örnek K14-42-E (katılımcı 14, yaş 42, erkek)]. Nitel verilerin güvenirlik hesaplaması Miles ve Huberman'ın (1994) güvenirlik formülüne göre yapılmış ve $\% 86$ bulunmuştur. Buna göre, güvenirlik sonuçlarının $\%$ 70'in üzerinde bulunması güvenilir olarak kabul edilmektedir. Böylece, görüşme formundan elde edilen bulguların güvenilir olduğu tespit edilmiştir. Nitel verilerin analizi ve modelleştirilmesinde "QSR Nvivo11"den istifade edilmiştir. Dağılımlar yüzde (\%) ve frekans (f) olarak verilmiştir.

\section{Sonuçlar}

Araştırmaya katılanların 42'si (58\%) kadın, 30'u (42\%) erkek, 7'si bekar ve 65 'i evlidir. Bunlardan $30-35$ yaş arası olanlar $22(30 \%), 36-40$ yaş arası olanlar $30(42 \%)$, 41-45 yaş arası olanlar $14(20 \%), 46$ ve yukarısı olanlar 6 (8\%) kişidir. Katılımcıların çocuk yaşları 6 ile 18 yaş arasında değişmektedir. Araştırmaya katılanların eğitim seviyeleri incelendiğinde; ilkokul mezunu 9 (13\%), ortaokul mezunu $20(28 \%)$, lise mezunu $32(44 \%)$ ve üniversite mezunu $11(15 \%)$ kişidir.

Teknoloji bağımlılığıyla ilgili yapılan araştırmalarda; özellikle internet, dijital oyunlar, cep telefonu, bilgisayar ve televizyon gibi teknolojik araçlar üzerinde kişilerin yaşamış oldukları, orantısız ve sürekli kullanım, vazgeçememe, engel olamama, yoksunluk yaşama, kontrolü sağlayamama ve bunlara bağlı olarak olumsuz durumlar yaşamaları gibi belirtilerin olabileceği tespit edilmiştir (İlhan ve Aydın, 2019; UNICEF, 2017; Yengin, 2019). Bu araştırmada da benzer sonuçlar elde edilmiştir. Buna göre ebeveynlerin ve çocukların hangi tür teknolojik araçlara bağımlı olduğunu ve ne kadar süreyle kullandıklarını tespit etmek maksadıyla yapılan incelemede elde edilen sonuçlar aşağıda belirtilmiştir.

$\mathrm{Bu}$ sonuçlara göre ebeveynlerin en çok internet kullandığ1, ikinci sırada akıllı telefonun $(\mathrm{f}=52, \% 72,7$ saat) geldiği, sonrasında bilgisayar ( $(=20, \% 28,7$ saat $)$ ve televizyonun ( $\mathrm{f}=22, \% 30,4$ saat) kullanıldı $\mathrm{g} 1$ tespit edilmiştir. Çocukların oranları incelendiğinde ilk sırada internetin ( $\mathrm{f}=70, \% 97,7$ saat) geldiği, sonrasında sirasıyla ak1ll telefonlar $(\mathrm{f}=57, \% 79,7$ saat $)$, tablet $(\mathrm{f}=16, \% 22,6$ saat) ve playstation $(\mathrm{f}=10, \% 14,6$ saat) geldiği tespit edilmiştir. Çocukların internette ve akıllı telefonlar başında geçirdiği zamanların çok fazla ve aileleriyle aynı ölçüde olduğu da görülmektedir. Ebeveynlerden bazılarının konuyla ilgili görüşleri şunlardır;
Ben en çok cep telefonu kullanıyorum, çocuklarım ise cep telefonu ve tablet arasinda gidip geliyorlar, tam emin değilim ama 5-6 saatlik bir süre söyleyebilirim (K3-35-K),

Cep telefonsuz bir şey yapamaz olduk, hepimiz aynı durumdayı, ben ortalama 6-7 saat telefon başındayım diyebilirim (K8-36-E),

Hepimizde cep telefonu var ve elimizden biraktığımı yok, günün 7-8 saati elimden düşmüyor (K12-38-K).

Ebeveynlerin ve çocukların teknolojik araçları kullanma nedenleri incelendiğinde; ebeveynlerin çoğunluğunun sosyal medyayı kullanmak maksadıyla, çocukların ise oyun oynama amacıyla teknolojik araçları kullandığ tespit edilmiştir. İkinci sırada ise ebeveynler ve çocukların teknolojik araçları müzik, film izleme/indirme amacıyla kullandığı belirlenmiştir. Sonrasında ise ebeveynlerin banka işlemleri, alışveriş yapmak, haberleri takip etmek, sıkıntıları unutmak, yalnızlığını bastırmak, eğlence ve cinsel amaçlı teknolojik araçları kullandığı saptanmıştır. Çocukların ise sohbet/görüntülü konuşma, e- posta amaçl1, eğlence amaçlı, ödev/araştırma amaçlı, paylaşım sitelerinde gezinme, alışveriş amaçlı teknolojik araçları kullandığı tespit edilmiştir. Ebeveynlerden bazılarının konuyla ilgili görüşleri şunlardır;

Eşim ve çocuklar evde olmadiğında facebook ve Instagram da vakit geçirmek hoşuma gidiyor. Onlar evde iken de baklyorum ama o kadar fazla değil. Çocukların da kullanmasina izin veriyorum bazen ödül olsun diye bazen de beni rahat bıraksın da işimi yapayım diye (K17-38-K),

Genelde akşamlart yemek yedikten sonra televizyonda bişey yoksa cep telefonunda gezinmeyi severim. Çocukların da oyun oynamasına izin veririm çünkü dışarısı artık çok tehlikeli evde otursunlar daha iyi (K22-42-E),

Eşimden ayrıldıktan sonra vaktimin çoğunu telefonda geçiriyorum. Internette gezinmek yalnızlığımı alıyor diyebilirim. Dışarı çıkacă̆ım zaman çocuklar gelmek istemiyor bu yüzden onlarin evde telefon ya da tablet kullanmasina izin veriyorum (K37-43-K),

Alışkanlık oldu herhalde, sürekli olarak cep telefonunun elimde olmasinı istiyorum, sanki o olmazsa kendimi yalnı hissedeceğim. En çok sosyal medya, youtube da müzik klibi izlemek, alışveriş yapmayı tercih ediyorum. Oğlumun da sürekli olarak Pubg diye bir oyunu var onunla oynadı̆̆ını biliyorum (K52-37-K).

Çocukların teknolojik araçlara çeşitli şekillerde erişebilmesi ve ailelerin buna müsaade etmelerinin çeşitli nedenleri bulunmaktadır. Buna göre; çocukların annebabasıyla birlikte ortak bir şeyler yapmaktan hoşlanmaması, bütün arkadaşlarının sanal âlemde olması ve orada vakit geçirmekten mutlu olması, herkes tarafindan kullanılan araçlar olması ve zararlı olabileceğinin düşünülmemesi, çoğunlukla evlerde aynı araçların bulunması ve çocukta olmazsa üzüleceğinin düşünülmesi, sigara, alkol, madde bağımlılığı gibi kötü alışkanlıklar edinmemesi için içeride vakit geçirmesinin tercih edilmesi, arkadaş çevresinin kötü alışkanlıklara sahip olması nedeniyle dışarıya çıkmasına müsaade edilmemesi ve vaktinin çoğunu teknolojik araçlar başında 
geçirmesinin daha güvenilir olduğunun düşünülmesi gibi sebeplerdir. Ebeveynlerin bu çeşit araçları kullanmalarına izin vermelerinin nedeni olarak vermiş olduğu cevaplardan bazıları şunlardır.

Oğlumun başarılı olması en çok istediğim şeydi. Koleji kazandiğ zaman ona cep telefonu alacağıma dair söz verdim. O da bunu başardı ve ben de sözümü tuttum (K63-37-E),

Benim çocuğum çok yaramaz, ne yapsam olmuyor. Ceza veriyorum sürekli ăgllyor isyan ediyor ben de ona tablet verince hemen susuyor. Ben de çareyi ona tablette oyun oynaması için izin vererek buluyorum (K57-34-K),

Açıkçası sunu söylemek istiyorum ben evde yalnızım, çocuğum da küçük, bana is yaptırmıyor, ben de rahat bir şekilde işlerimi yapabilmek için onun tablette oyun oynamasina izin vermek zorunda kallyorum (K51-32-K),

Bazen insanın canı dışarı çıkıp bir şeyler yapmak istiyor ama çocukların gelemeyeceği yerler var. O yüzden onları evde birakıp eşimle birlikte dışarı çıkarız. Çocuklar da evde bilgisayar ya da internet başında oluyorlar (K38-41-E),

Eve misafir geliyor bizim çocuklar daha beter gürültü yapmaya başllyorlar. Gelenler de yanlış anlamasin diye çocukları odalarına gönderiyoruz, onlarda muhtemelen telefon ya da bilgisayarda bir şeyler yapıyorlar ki hiç sesleri çlkmiyor bizde rahat rahat sohbet ediyoruz (K29. 43-E),

Benim çocuğum biraz içine kapanık, pek fazla da arkadaşı yok zaten. Dışarı çıkmak da istemiyor, sürekli cep telefonu ya da bilgisayarda bir şeyler yapıyor, o yüzden ben de buna pek ses çıkaramıyorum. Dışarı git desem nereye gidecek (K47-37-K),

Teknolojik araçların çocuklar ve yetişkinler üzerinde birçok olumsuz etkileri olabilmektedir. Bu etkilerin neler olabileceğinin belirlenmesi maksadıyla ebeveynlere "Teknolojik araçların sizde ve çocuklarınız üzerinde ne gibi olumsuz etkileri olabilir" şeklinde bir soru yöneltilmiş ve şu sonuçlar elde edilmiştir. Çocuklarda son zamanlarda kendini ifade edememe, içine kapanma, fazla konuşmama, özgüven eksikliği, yalnız kalma isteği, sosyal aktivitelere katılmama veya geri durma, iletişim sorunları, agresiflik, konsantrasyon kayb1, sık1lganlık, huzursuzluk, performans düşüklüğü (derslerde ve hareketlilikte), sosyal ortamlardan çabuk sıkılma, göz bozuklukları, zamanının çoğunu teknolojik araçlarla geçirme, eklem bozuklukları (el parmakları, bilek, dirsek, boyun, omuz), sırt, bel, kemik ve kas yapısında bozulmalar ve yorgunluk, sinirlilik, saldırganlık, yalan söyleme, dikkat eksikliği, uyku sorunları gibi sorunlardır. Ebeveynlerin kendilerinde görülen sorunlar ise yukarıda belirtilenlere ilave olarak; fiziksel ve ruhsal sorunlar, performans kaybı, iş yerinde konsantrasyon sorunları, mutsuzluk, uykusuzluk, ailevi sorunlar, zaman sorunu, yalnız kalma isteği, sosyal aktivitelerden zevk almama, agresiflik, huzursuzluk, depresyon, bunalt1, sinirlilik, saldırganlık gibi sıkıntılar yaşandığ tespit edilmiştir. Konuyla ilgili ebeveynlerin bazılarının vermiş olduğu cevaplar şunlardır;
Cep telefonu ve bilgisayar başındayken sürekli olarak boynum ve omuzum ağriyor. Fizik tedaviye gittim çok gittim ama sonuç alamadım. Biraz düzelme oluyor ama sonra yine aynı ağrllar devam ediyor. Oğlumun ise gözlerinde problem çıtıtı ve gözlük takmaya başladı. Doktor, sürekli olarak cep telefonu kullandığ iç̧in olduğunu söyledi $($ K21-37-K),

Yapacak başka bir şey bulamayınca internette vakit geçiriyorum. Bazen gece geç saatlere kadar sürüyor. Sabahları uyanmasi da zor oluyor ve mesaiye geç kaliyorum, uykusuz olduğum için mesaide de sorunlar yaşıyorum. Çocuklarımla ilgili de bazı sorunlar yaşadığımızı söyleyebilirim. Özellikle büyük olanlar aramız bayağı kötüledi. Odasından çımıyor ve birlikte yemek dahi yiyemiyoruz. Sürekli olarak bilgisayar başında ve internette vakit geçiriyor. Konuşmaya çekinir oldum çünkü her seferinde bana ters cevaplar veriyor ve agresiflessiyor (K31-44-E),

O kadar monoton bir hayat yaşlyoruz ki evden işe, işten eve diyebilirim. Neredeyse her günümüz böyle geçiyor. Hafta sonlar ise hiçbir yere gitmez olduk. Çocukların ilk sorduğu gideceğimiz yerde internet var mi, yoksa gelmiyorlar ya da geldiklerinde hemen sıkllip dönmek isterler. Bizde evden başka bir yerde vakit geçirmez olduk. Evde olunca da cep telefonu, televizyon ve internet arasında kısır döngü yaşıyoruz. Ev ortamında hiç birlikteliğimiz kalmadl. Herkes bir odada kendi bașına bir şeyler yapıyor. Ne aile bütünlüğ̈̈ kald, ne birliktelik ne de mutlu bir şeyimiz (K7241-K).

Teknolojik araçların uzun süre kullanımı çocuklarda gelişim sorunları yaşanmasına ve akademik başarısızlığa neden olmaktadır. Bu çalışmada da çocuklardaki ders başarı durumunu etkileyen sebeplerin belirlenmesi maksadiyla bir soru sorulmuş ve çeşitli sonuçlar elde edilmiştir. Bu sonuçlardan bazıları şunlardır. Teknolojik araçlarla çok fazla zaman geçirme ve sorumluluklarını yerine getirememe ya da aksatma (yemek, uyku düzeninde bozulma veya ders çalışma sürecinde yaşanan problemler), teknolojik araçlar başında vakit geçirmekten kaynaklı fiziksel sorunlar yaşama, teknolojik araçların kullanılmadığı zamanlarda dahi sürekli onu düşünme, birçok sorun (sınavlarda başarısızlık, ceza alma vb) yaşamasına rağmen teknolojik araçları kullanmaya devam etme ve bırakamama, teknolojik araçlardan mahrum kalınca gergin, sinirli ve boşlukta kalmış gibi hissetme, oyun ve zevk verici olanakların gerçek hayata göre daha uygun ve erişiminin kolay oluşu, içe kapanık ve sosyal olmama, arkadaşları/akranları tarafından dışlanma ve yalnızlık, aile içindeki sorunlar ve iyi vakit geçirememe, spor, sağliklı yaşam ve sosyal ilişkileri geliştirebilecek ortamlardan uzak olma gibi nedenler çocukların akademik başarısına ve gelişimlerine etki edebilmektedir. Konuyla ilgili ebeveynlerin bazılarının vermiş̧ olduğu cevaplar şunlardır;

Çосй̆umu, bilgisayar ve cep telefonundan ayıramıyorum. Her seferinde tartışma yaşıyoruz ve aramız gittikçe kötüleşiyor. Birlikte yemek dahi yiyemiyoruz, gece geç saatlere kadar bilgisayarda oyun oynuyor ve uykusuz kalyyor. Sabahları okul için uyandırmakta çok 
zorlaniyorum. Dersleri de bu sene geçen seneye göre çok kötü durumda. Ne ders çalışlyor ne de ödev yapıyor. Okula gitmek zorunlu olmasa ona da gitmeyecek. Ne yapsam bir türlü bu durumu düzeltemiyorum (K69-42-E),

Oğluma cep telefonunu çok kullandiğ için ceza verdim. Süre belirtmedim ama uzun bir süre cep telefonunu vermeyeceğimi söyledim. Çünkü sürekli olarak cep telefonu ve oyunla meşgul olduğundan derslerinde düşük notlar almaya başladı. Fakat son zamanlarda bayağl gergin ve sinirli hareketler yapmaya başladi. Geçenlerde konuştuğumda ise kendini sanki boşlukta kalmış gibi hissettiğini söyledi. Bu kadar etkileyeceğini hiç düşünmemiştim (K53-46-E),

Oturduğumuz evin şehirden dişarıda olması nedeniyle çocuğumun etrafinda bir arkadaşı yoktur. Sürekli olarak odasindadir ve ya cep telefonuyla oyun oynar ya da bilgisayar başında vakit geçirir. $O$ kadar uzun vakit geçiriyor ki bizde onu unutuyoruz. Lise son sinif oldu ve üniversite sinavina hazırlanmasl gerekiyor ancak pek ümidim yok çünkü hiç ders çalışmıyor. Zaten kendisi de kazanıp kazanamayacağıyla ilgili herhangi bir endişe içinde değil. Askere gideceğim ben diyor ama askerden sonrasını hiç düşünmüyor (K46-42-E).

\section{Tartışma}

$\mathrm{Bu}$ araştırmadan elde edilen bulgular 1şı̆̆ında teknolojik araçların hayatımızın her köşesine yerleştiği ve bunlardan vazgeçebilmenin giderek zorlaştığ tespit edilmiştir. Böylece hem ebeveynler hem de çocukları teknolojik araçlara bağımlı hale gelmiş ve bu bağımlılık onların fiziksel ve zihinsel gelişimleri ile aile, sosyal hayat, okul ve iş yaşantılarını olumsuz yönde etkilemeye başlamıştır. Teknoloji bağımlılığının olumsuz etkileri üzerine yapılan çeşitli araştırmalarda da benzer sonuçlar elde edilmiştir. Buna göre teknolojik araçların hayatı daha sanal bir hale dönüştürdüğü, günlük işlerin aksatıldığı, zaman kaybı ve boş zamanla ilgili sorunların oluştuğu, ruhsal ve bedensel sağlık sorunlarının arttığı tespit edilmiştir (Elshaly ve ark., 2019; Granic, Lobel ve Engels, 2014; İşçibaş̧1, 2011; Kuss ve ark., 2013; Müezzin, 2017; Nalwa ve Anand, 2003; Palmer, 2015; Salehan ve Negahban, 2013)

Teknolojik araçların bireylerde dikkat dağınıklığı, kendini kaybetme, düşüncede zayıflama ve göz sağlığı gibi çok ciddi sağlık sorunlarına neden olduğu da belirlenmiştir (American Academy of Pediatrics, 2016; Epstein, 2015; Yılmaz, 2019; Yusufoğlu, 2017). Bunlardan Sayan'ın (2016) çalışmasında teknolojik araçların aşırı kullanımının çocuklarda çeşitli ruhsal, bedensel ve bilişsel problemler ortaya çıkardığı, Günüç ve Adli'nin (2018) çalışmasında bu araçların çocukların davranışlarını ve psikolojilerini olumsuz etkilediği, Yel ve Korhan'ın (2015) çalışmasında da tablet ve bilgisayar kullanımındaki artışı çocukların kas-iskelet sistemlerinde sorunlar görülmesine, boyun, omuz, bel ve sırt bölgelerinde rahatsızlıkların oluşmasına neden olduğu tespit edilmiştir.

Bununla birlikte Petersen ve Johnston'un (2015) çalışmasında tam tersi bir sonuç bulunmuştur. Buna göre teknolojik araçların sürekli kullanımı insan yaşamını olumlu yönde etkilediği tespit edilmiştir. Lissitsa ve
Chachashvili-Bolotin'in (2016) çalışmasında da insanların internetle meşgul olmasının yaşam kalitesini artırdığı sonucuna ulaşılmıştır. Bir başka çalışmada teknolojik araçların eğitim ve öğretimde çocukların daha çok ilgisini çektiği, motivasyonunu artırdığı, anlaşılması zor olgu ve problemleri basitleştirip somutlaştırmasıyla olumlu etkisinin olduğu tespit edilmiştir (Vural, 2014). Çocukların ebeveyn veya öğretmen denetiminde teknolojik araç kullanmaları halinde akıl yürütme, davranış planlama, görsel-motor koordinasyon ve görsel bellekte artış sağlayabileceği sonucuna da ulaşılmıştır (Dale-McManis ve Gunnewig, 2012).

$\mathrm{Bu}$ araştırma sonucundan elde edilen bir başka bulguda ise özellikle internet, cep telefonu, bilgisayar ve dijital oyunların sunduğu sanal ortam, eğlence ve hoşnutluk gerçek yaşama tercih edilir duruma gelmiştir. Öyle ki günlük olarak neredeyse 7-8 saatlik süreler bu araçların başında geçirilmekte ve diğer faaliyetlere (aile birlikteliği, yemek, uyku, dinlenme, ders çalışma, sosyal ve sportif faaliyetler vb) bile zaman kalmamaktadır. İnternet kullanımıyla ilgili Dünya ortalamasının 6 saat 42 dakika olduğu bir araştırmada Almanya'da yaklaşı 4,5 saat, İspanya'da 5 saat 18 dakika, ABD'de 6,5 saat ve Türkiye'de 7 saat 15 dakikalık günlük internet kullanıldığı sonucuna ulaşılmıştır (We are social, 2018). Dünya genelindeki bu artışın akıllı telefonlardaki çeşitlilik, fiyat ve donanım özellikleri ile mobil iletişimle internete erişim imkânlarının genişlemesi olduğu değerlendirilmektedir. $\mathrm{Bu}$ araştırmada da İnternete en fazla akıllı telefonlar ile bağlanıldığından akıllı telefon kullanılma oranının arttı̆̆ 1 görülmüştür. Global Web Index'in 2018 yılındaki verilerine göre de bireylerin günlük internet destekli cihaz ve hizmetleri kullanarak yaklaşık 7 saatlik bir vakit geçirdiği tespit edilmiştir. $\mathrm{Bu}$ verilere göre de bireylerin uyanık kaldıkları ortalama zamanın yaklaşık üçte birinin internet başında geçirildiği ve böylece aile içi iletişimde sorunlar, yemek alışkanlıklarının değişmesi, uyku ve dinlenme sorunları, akademik başarı gibi sorunların derinleştiği ortaya çıkmıştır (Dhir, Chen, ve Nieminen, 2015; Işıklı ve Küçükvardar, 2017; Işıklı, 2018; İlhan ve Aydın, 2019, Korkut, 2016; Sefton-Green ve Buckingham, 1998; Techatassanasoontorn ve Tanvisuth, 2010; Vaghefi ve Lapointe, 2014; Zwanenburg, 2013).

Samaha ve Hawi'nin (2016) çalışmasında ise teknolojik araçlar ile yaşam kalitesindeki düşüş arasında anlamlı ilişski bulunmamıştır. Vodanovich ve arkadaşlarının (2010) çalışmasında da yeni neslin teknoloji içinde doğduğu ve teknolojik araçların onların yaşam tatminlerini büyük ölçüde olumlu yönde etkilediği sonucuna ulaşılmıştır. Yan'ın (2018) çalışmasında da teknolojik araçların olumlu etkilerinin olduğu ve bireylerin bilişsel, sosyal-duygusal ihtiyaçlarını karşılamada etkili olduğu tespit edilmiştir (Yan, 2018).

Ebeveynlerin sosyal medya (facebook, instagram, twitter, youtube, vb.), internet ve akıllı telefonları daha fazla kullanmaları aile, iş ve sosyal ortamlardan eskiye oranla zevk almamaları ve sanal dünyanın cazibesine kendilerini kaptırmaları çocuklarını da etkilemekte ve olumsuz model olmalarına da neden olmaktadır. Konuyla ilgili yapılan çeşitli araştırmalarda da teknolojik araçlar başında geçirilen vaktin artması ile gerçek hayatta yapılan etkinliklerin azaldığı, aile, iş, sosyal çevrede sorunlar başladığı ve çocukların da bundan olumsuz yönde etkilendiği sonuçlarına ulaşılmıştır (Andreassen, 
Pallesen ve Griffiths, 2017; Ekşi ve Ümmet, 2013; TBMM, 2012; Van Deursen, Bolle, Hegner ve Kommers, 2015; Wang, Ho, Chan ve Tse, 2015; Wittek ve ark., 2015).

Araştırma sonuçlarından yola çıkarak teknoloji bağımlılığının önlenmesine yönelik çeşitli öneriler geliştirilmiştir. Teknolojinin bilinçli kullanılması halinde faydaları zararlarını geçebilmektedir. Böylece diğer bağımlılık türlerinden birine dönüşmemesi için çeşitli eğitimler, daha fazla araştırmalar yapılmalı, farkındalık sağlanmalı ve kontrollü kullanım sağlanarak başa çıkmada zorlanılan durumlarda uzman desteği alınmalıdır. Ebeveynlerin olumsuz model olduklarıyla ilgili yüzleşmeleri gerektiği ve çocuklarını bu bağımlılıktan kurtarmak amaciyla teknolojik araç kullanımını sınırlandırma ve içerik kontrolüne özen göstermeleri gerekmektedir. $\mathrm{Bu}$ sebeple öncelikle kendileri teknoloji bağımlılı̆̆ından kurtulmaları konusunda tedavi görmeli sonrasında ise çocuklarına bu yönde eğitimler veya tedaviler aldırmalıdırlar.

Aile içi iletişimin ve birlikte geçirilen zamanın arttırılması, çocukların dışarıya çımalarının teşvik edilmesi ve arkadaşları ile geçirilen zamanın da arttırılarak gerekirse onlara bu ortamların sağlanması ve çocukların sosyalleşebilmeleri için sosyal, kültürel ve sportif faaliyetlere yönlendirme ve bu faaliyetlerle meşgul olmalarının sağlanması önerilmektedir. Teknolojik araç kullanımında yaşına uygun bir kota veya sınır konulmalı ve buna uyulmalı, zaman ve içerik konusu takip edilmeli, gerekirse zaman konusunda değişiklikler yapılmalı, araştırma, ödev/ders gibi çalışma amac1 güdülüyorsa süre sınırlaması buna göre değerlendirilmelidir.

Çocukların erişim sağladığı internet siteleri, şiddet veya uygunsuz cinsel içerikli oyunlar takip edilmeli, filtre veya güvenlik konulmalı, girdikleri siteler, kimlerle iletişime geçtikleri gibi hususlar takip edilmeli, gerekirse çocuklarla bu konular görüşülmeli ve bilinçlenmeleri sağlanmalıdır. Kendi sorunlarıyla baş etmekte zorlanan veya bunlardan kaçarak çözüm bulmak isteyen ebeveynlerin çocukları için de olumsuz model olacağı unutulmamalı, erken yaşlarda çocuklara teknolojik araçlar alıştırılmamalı ve çocuklar bağımlılığa yöneltilmemelidir.

\section{Kaynaklar}

Aksu, Z.U. ve Iş̧ılı, Ş. (2019). Teknolojik Zehirlenme, Semptomları ve Teknolojik Düzen. Uluslararası Bilişim, Teknoloji ve Felsefe Dergisi, 2(2), 58-87.

American Academy of Pediatrics (2016). Media and young minds. Pediatrics, 138(5), 1-8.

Anandi, B.S. ve Gududur, A. (2018). Technology addiction and associated health problems among medical students in Kalaburagi District. Natl J Community Med, 9(4): 294-299.

Andreassen, C.S., Pallesen, S. ve Griffiths, M.D. (2017). The relationship between addictive use of social media, narcissism, and self-esteem: findings from a large national survey. Addictive Behaviors, 64 (1): 283-293.

Aslan, E. ve Yazici, A. (2016). Internet addiction among university students and related sociodemografic factors. Clin Psychiatry, 19, 109-117. doi:10.5505/kpd.2016.03511.

Bachleda, C. ve Darhiri, L. (2018) Internet addiction and mental and physical fatigue. Int Technol Manag Rev., 7(1), 25-33.

Dale-Mcmanis, L., ve Gunnewig, S.B. (2012). Finding the education in educational technology withearly learners. Technology and Young Children, 67(3), 14-24.

D'Arcy, J., ve Gupta, A. (2014). Reflecting on the "dark side" of information technology use. Communications ofthe Association for Information Systems, 35, 109-118.

Dhir, A., Chen, S. and Nieminen, M. (2015). Predicting adolescent internet addiction:the roles of demographics, technology accessibility, unwilligness to communicate and sought internet gratifications. Computers In Human Behaviour, 51, 24- 33.

Epstein, A. S. (2015). Using technology appropriately in the preschool classroom. https://ccie media.s3.amazonaws.com/exchangefocus/001exchangefocus.pdf. [Erişim tarihi: 26.12.2019].

Ekşi, F. ve Ümmet, D. (2013). Bir kişilerarası iletişim problemi olarak internet bağımlılı̆̆ 1 ve siber zorbalık: psikolojik danışma açısından değerlendirilmesi. Değerler Ĕ̆timi Dergisi, 11 (25), 91-115.

Elsalhy, M., Miyazaki, T., Noda, Y., Nakajima, S., Nakayama, H., Mihara, S., Kitayuguchi, T., Higuchi, S., Muramatsu, T., ve
Mimura, M. (2019). Relationships between Internet addiction and clinicodemographic and behavioral factors. Neuropsychiatric Disease and Treatment, Volume 15, 739-752.

Erses, T. ve Müezzin, E. (2018). İnsani değerler psiko-eğitim programının ergenlerde internet kullanımına etkisi. Uluslararası Beşeri Bilimler ve Eğitim Dergisi, 4(7), 313-326.

Gerhart, N. (2017). Technology addiction: how social network sites impact our lives. Informing Science: the International Journal of an Emerging Transdiscipline, 20, 179-194. http://www.informingscience.org/Publications/3851] [Erişim tarihi: 08.11.2019].

Granic, I., Lobel, A., ve Engels, R.C. (2014). Thebenefts of playing video games. AmericanPsychologist, 69(1), 66-78.

Goodwin, K. (2018). Dijital dünyada çocuk büyütmek. (çev. Tülin Er), İstanbul: Aganta Kitap Yayınevi.

Günüç, S. ve Atli, S. (2018). 18-24 aylık bebeklerde teknolojinin etkisine yönelik ebeveyn görüşleri. Addicta: The Turkush Journal on Addictions 5(2), 1-22.

Haug, S., Castro, R.P., Kwon, M., Filler, A., Kowatsch, T., Schaub, M.P. (2015). Smartphone use and smartphone addiction amongyoung people in Switzerland. J Behav Addict, 4(4), 299307.

Hamissi, J.,Hosseini, M., Babaie, M. ve Babaie, F. (2013).There lations hipbetween emotion alintelli gence andt echnology addiction among university students. International Journal of Collaborative Research on Internal Medicineand Public Health, 5, 310-319.

Iş1klı, Ş. (2017). Teknolojinin Yan Etkileri.Sophos Akademi Tv:htps://www.youtube.com/watch?v=2o-2 41Z Hs [Erişim tarihi: 10.11 .2019$]$

Işıkl1, Ş. ve Küçükvardar, M. (2017). Biliş̧im devrimi: teknolojinin felsefi ve sosyolojik analizi. Ankara: Birleşik Kitabevi Yayınları.

İlhan, V. ve Aydın, H. (2019). Okul topluluğu üyelerinin internet ve mobil iletisim teknolojileri ile etkileșimin olası riskleri üzerine düşünceleri. Uluslararası Sosyal Araștırmalar Dergisi, 12(64), 755-772. 
İsç̧ibașı, Y. (2011). Bilgisayar, internet ve video oyunları arasında çocuklar. Selçuk Üniversitesi İletişim Fakültesi Akademik Dergisi, 7(1), 122-130.

Korkut, K. (2016). Lise ögrrencilerinin sosyal medya yoluyla geliştirdiği tutumlar. sakarya/ kaynarca örneği. Yüksek Lisans Tezi. Sakarya: Sakarya Üniversitesi.

Kuss, D. J., Griffiths, M. D., ve Binder, J. F. (2013). Internet addiction in students: Prevalence and risk factors. Computers in Human Behavior, 29(3), 959966.https://doi.org/10.1016/j.chb.2012.12.024 [Erişim tarihi: 07.11.2019].

Lissitsa, S., ve Chachashvili-Bolotin, S. (2016). Life satisfaction in the internet age: Changes in the past decade. Computers in Human Behavior, 54, 197-206.

Miles, M.B., ve Huberman, A.M. (1994). Qualit ative data analysis: an expandedsourcebook (2nd ed.). Sage: California.

Müezzin, E. (2012). There lation ship between internet addiction and psychologicalsy mptoms, International Journal of Global Education, 1(2).

Müezzin, E. (2017). An investigation of highschoolstudents' internet addiction withre spect towith drawal, controlling difficulty, disorder in function alityand socialisolation. Sakarya University Journal of Education, 7(3), 541-551.

Nalwa, K., ve Anand, A. (2003). Internet addiction in students: a cause of concern. Cyber Psychology and Behavior, 6, 653-656.

Öztürk, M. (2017). Teknolojiye Yerinde Yeterince. TBM Alan Kitaplığı Dizisi: 9 (7.Baskı). İstanbu: Kültür Sanat Basımevi.

Palmer, S. (2015). Toxicchildhood: how the modern world is dama gingour children and what we can do about it. Los Angeles, CA: Orion.

Petersen, C., ve Johnston, K.A. (2015). The impact of social media usage on the cognitive social capital of university students. Informing Science: The International Journal of an $\begin{array}{llll}\text { Emerging } & \text { Transdiscipline, } & 18, & 1-30 .\end{array}$ https://www.informingscience.org/Publications/2160 [Erişim tarihi: 9.11.2019].

Salehan, M., ve Negahban, A. (2013). Social networking on smartphones: when mobile phones become addictive. Computers in Human Behavior, 29(6), 2632-2639.

Samaha, M. ve Hawi, N.S. (2016). Relationships among smartphone addiction, stress, academic performance, and satisfaction with life. Computers in Human Behavior, 57, 321325 .

Sayan, H. (2016). Okul öncesi eğitimde teknoloji kullanımı. 21. Yüzyllda Eğitim ve Toplum, 5(13).

Sefton-Oreen, J. ve Buckingham, D. (1998). "Digitalvisions: children's "creative" uses of multimedia technologies", in J. Sefton-Oreen (ed.) Digital Diversions, pp. 62-83. London: UCL Press.

Sert, G., Kurtoğlu, M., Akınc1, A. ve Seferoğlu, S.S. (2012). Öğretmenlerin teknoloji kullanma durumlarını inceleyen araștırmalara bir bakıș: bir içerik analizi çalıșması, Akademik BilişimDergisi. [http://yunus.hacettepe.edu.tr/ sadi/yayin/AB12 Sert-Kurtoglu-Akinci-Seferoglu_Icerik Analizi.pdf [Erişim tarihi: 12.10.2019].

Şahin, S., Özdemir, K., Ünsal, A., ve Temiz, N. (2013). Evaluation of mobile phone addiction level and sleep quality in university students. Pakistan Journal Of Medical Sciences, 29(4), 913-918.

Tarafdar, M.,Gupta, A., ve Turel, O. (2013). Thedarkside of information technology use. Information Systems Journal, 23(3), 269-275.

TBMM. (2012). Bilgi toplumu olma yolunda başta biliş̧im sektöründeki gelişmeler olmak üzere internet kullanımının gençler ve çocuklar üzerindeki etkilerini araștırma komisyonu. Ankara: Türkiye Büyük Millet Meclisi.

Techatassanasoontorn, A.A., ve Tanvisuth, A. (2010). IS use and quality of life: A conceptu alization and empir-ical investigation. AIS Transactions on Human-Computer Interaction, 2(2), 26-54.

UNICEF, (2017). Dünya Çocuklarının Durumu 2017. New York, Birleşmiş Milletler Çocuklara Yardım Fonu. http://www.unicef.org.tr/files/bilgimerkezi/doc/SOWC_2017_S UM_TR.pdf [Erişim tarihi: 18.10.2019].

Vaghefi, I., ve Lapointe, L. (2014). When too much usage is too much: Exploring the process of IT addiction. Proceedings of the 47th Hawaii International Conference on System Sciences IEEE. https://doi.org/10.1109/HICSS.2014.553 [Erişim tarihi: 10.11.2019].

Van Deursen, A.J., Bolle, C.L. Hegner, S.M. ve Kommers, P.A. (2015).Modeling habitual and addictive smartphone behavior: the role of smartphone usage types, emotional intelligence, social stress, self-regulation, age, and gender. Computers in Human Behavior, 45: 411-420.

Vodanovich, S., Sundaram, D., ve Myers, M. (2010). Research commentary: Digital natives and ubiquitous in-formation systems. Information Systems Research, 21(4), 711-723.

Vural, B. (2014). Eğitim-öğretim teknoloji ve materyal kullanımı. İstanbul: Hayat Yayıncılık.

Wang, C.W., Ho, R.T., Chan C.L., ve Tse, S. (2015). Exploring personality characteristics of chinese adolescents with internetrelated addictive behaviors: trait differences for gaming addiction and social networking addiction. Addictive Behaviors, 42: 32-35 wearesocial.com (2019).

Digital 2019: Global Internet Use Accelerates. https://wearesocial.com/blog/2019/01/digital-2019globalinternet-use-accelerates [Erişim tarihi: 10.11.2019].

Winkler, A.,Dörsing, B., Rief, W., Shen, Y., ve Glombiewski, J.A. (2013). Treatment of internet addiction: a meta-analysis. Clinical Psychology Review, 33(2), 317-329.

Wittek, C.T., Finserås, T.R., Pallesen, S., Mentzoni, R.A., Hanss, D.,Griffiths, M.D. ve Molde, H. (2015). Prevalence and predictors of video gameaddiction: a study based on a national representative sample of gamers. International Journal of Mental Health and Addiction, 14: 672-686.

Yan, Z. (2018). Child and adolescent use of mobile phones: An unparalleled complex develop mental phenomenon. Child Development, 89(1), 5-16.

Yayla, O.T. (2017). Analogtan dijitale iletişim teknolojilerinin gelişimi: sosyal medya ve sosyal değişim. Yüksek Lisans Tezi. İstanbul Ticaret Üniversitesi Sosyal Bilimler Enstitüsü, İstanbul.

Yel, B.E. ve Korhan, O. (2015). Eğitsel amaçlı masaüstü/dizüstü/tablet bilgisayar kullanımında öğrencilerin kas iskelet hareketleri ve olası kas iskelet rahatsızlıkları. Süleyman Demirel Üniversitesi Mühendislik Bilimleri ve Tasartm Dergisi, 3(3), 631-638.

Yengin, D. (2019). Teknoloji bağımlılığı olarak dijital bağımlılık. The Turkish Online Journal of Design, Art and Communication, 9(2), 130-144.

Yılmaz, Z. (2019). 18-25 yaş arast üniversite ögrencilerinde internet bağımlılı̆̆ının depresyon ve yalnızlıkla ilişkilendirilmesi. Yayımlanmamıș doktora tezi, İnönü Üniversitesi Tıp Fakültesi, Malatya.

Yusufoğlu, Ö.S. (2017). Boş zaman faaliyeti olarak akıllı telefonlar ve sosyal yaşam üzerine etkileri: üniversite öğrencileri üzerine bir araştırma. İnsan ve Toplum Bilimleri Araştırmalar Dergisi, 6, (5), 2414-2434.

Zwanenburg, S.P. (2013). Information technology addiction: construct development and measurement. Pro-ceedings of the 34th International Conference of Information Systems (pp. 112). 